\title{
Cognitive-Pragmatic Strategies for English Translation of Colloquial Metaphors in Political Discourse
}

\author{
Chen Yulian*, Zhang Yingxian \\ Email address: \\ yulianchen2003@163.com (Chen Yulian) \\ ${ }^{*}$ Corresponding author
}

South China Business College, Guangdong University of Foreign Studies, Guangzhou, China

To cite this article:

Chen Yulian, Zhang Yingxian. Cognitive-Pragmatic Strategies for English Translation of Colloquial Metaphors in Political Discourse. International Journal of Applied Linguistics and Translation. Vol. 6, No. 3, 2020, pp. 89-95. doi: 10.11648/j.ijalt.20200603.16

Received: August 21, 2020; Accepted: September 1, 2020; Published: September 25, 2020

\begin{abstract}
The colloquial metaphor is a distinguishing feature of Chinese political discourse. Relevance theory of cognitive pragmatics is instructive and significant for the English translation of colloquial metaphors in political discourse, according to which, in the process of metaphor translation, the translator is supposed to take into consideration the cognitive context and pragmatic-communicative intention of the author, and also the cognitive environment of the target readers. Taking the Chinese and English version of the second volume of Xi Jinping: The Governance of China as an example, the present study explores the translation strategies for the colloquial metaphors in Xi Jinping's speeches from the perspective of cognitive pragmatics. The results show that different cognitive-pragmatic translation strategies can be flexibly adopted, such as maintaining the coherence of the cognitive effect between the author and the target readers through literal translation, enhancing the accessibility of their cultural context via free translation, and strengthening the relevance between their cognitive-cultural context by means of zero translation. Appropriate cognitive-pragmatic strategies are useful for the realization of optimal relevance between the source text and the translation, promoting foreign readers' understanding of the connotation of colloquial metaphors and the speaker's pragmatic intentions, and better facilitating the spread of Chinese culture.
\end{abstract}

Keywords: Political Discourse, Colloquial Metaphor, Cognitive Pragmatics, Translation Strategies

\section{Introduction}

Lakoff \& Johnson, in their classic work Metaphors We Live $b y$, bring metaphor into the cognitive category and hold that the conceptual systems of human thought and action are mostly metaphorical [1]. Metaphor is a universal phenomenon in all languages, and it has high application value. It can visualize abstract concepts and make boring language interesting. The study of metaphor has a long history and has experienced a turn from rhetoric to linguistics. Metaphor has become the object of study by language philosophers, semanticists, pragmatists and cognitive linguists, which has evolved from a philosopher's discussion of the universe and description of the world to a special means of conveying meaning in a dynamic context. Although any metaphor is apparently embodied as a certain language rhetoric, but indirectly implies profound psychological activities and ways of thinking, while psychological phenomena and practical behavior are the deep-level display of cultural phenomena [2].
Therefore, the translation of metaphor must be a very complicated process, which is influenced by many factors, such as the cultural background and mode of thinking of the author, the translator and the reader. In today's society, language and culture are becoming more and more diversified and complicated, and metaphor translation is facing more and more challenges. Researchers of metaphor translation agree that metaphor translation should not be limited to a single perspective, but should be dealt with dynamically and flexibly by considering language, culture and cognition in the actual context [3]. For this reason, it is believed that relevance theory [4] proposed by Sperber \& Wilson is instructive to metaphor translation, though it is not a special translation theory. In particular, it provides guidance for the interpretation and translation of colloquial metaphors with profound historical background and cultural implications in a specific context. 


\section{The Basic Characteristics of Colloquial Metaphors in Chinese Political Discourse}

As an indispensable cognitive tool and mode of thinking for human beings, metaphor not only widely exists in literary works, but also frequently appears in the discourse of politicians, to be favored by them. Political metaphor contains rich ideology, is an important way to construct political discourse, and plays an important role in political rhetoric and political thought. As an important tool for expressing political stands, shaping national image and improving international relations, it can help to explain complex political concepts, arouse the emotions of the audience, guide value judgment and convey the people-oriented ruling concept [5]. The use of metaphorical structures in Chinese political discourse has always been evident in the speeches of various leaders. For example, Mao Zedong has applied "纸老虎" which is usually translated as paper-tiger nowadays to refer to those who appear to be powerful but are actually powerless. Deng Xiaoping mentions "不管白猫黑猫，捉到老鼠就是好猫" in his speech to emphasize that sometimes it is unnecessary to pay too much attention to details once the result is good. And $\mathrm{Xi}$ Jinping uses "鞋子合不合脚, 自己穿了才知道" to illustrate his point that only the people of a country have the most say in whether its development path is appropriate or not, just as people won't know whether the shoes fit until they wear them. These metaphors illustrate the political thinking, stance and philosophy of the Chinese government at different times.

In the context of shaping the image of China as a great power, promoting the spread of Chinese culture and building cultural self-confidence, Xi Jinping's speech is rich in metaphorical expressions with Chinese cultural characteristics, helping to construct a unique discourse system of habitual style, to convey his political and state-building ideas to readers or listeners, so as to establish China's national image. These metaphors stem from the familiar concepts of life practice and lead people to perceive, experience, imagine and understand the abstract political concepts [6]. There are many popular colloquial metaphors among them. In August 2014, for instance, $\mathrm{Xi}$ quoted Deng Xiaoping at a symposium commemorating the 110th anniversary of Deng Xiaoping's birth, stressing that reform and opening up should be bold and not like "小脚女人" (women with bound feet). In January 2015, during the twenty collective study sessions of the eighteenth Politburo of the Communist Party of China (CPC), $\mathrm{Xi}$ proposed that priority should be given to key areas in the work, instead of"眉毛胡子一把抓" which is a metaphor for a lack of priority. And in his speech at the opening ceremony of the World Economic Forum annual meeting in January 2017, $\mathrm{Xi}$ applied "牵牛鼻子" (to handle the critical problems) to stress that China will hold the nose of innovation and promote the strategy of innovation-driven development. In Xi's speeches, actually, an endless session of colloquial metaphors exist which are similar to "小脚女人", "眉毛胡子一把抓", and "牵牛鼻子".

Although these colloquial metaphors come from ordinary language, they contain judgments, attitudes and emotions. They are rich and profound in connotation and have unique cognitive and pragmatic functions, which helps promote identification between the speaker and the listeners. The correct interpretation and English translation of these metaphorical expressions will help readers at home and abroad better grasp the meaning and intention of Xi's speech, better promote the spread of Chinese culture, and establish a positive national image. In this paper, the author makes a contrastive analysis of the Chinese and English versions of the second volume of 《习近平谈治国理政》(Xi Jinping: The Governance of China) and explores the translation strategies for the colloquial metaphor from the perspective of cognitive pragmatics.

\section{Theoretical Basis for Metaphor Translation}

Relevance theory has long been regarded as a landmark achievement of cognitive pragmatics. Although relevance theory does not directly explain translation, as a powerful theory, it provides a unified theoretical framework for this complex phenomenon [7].

\subsection{The Contextual View of Relevance Theory}

Relevance theory holds that communication is a relevance-oriented cognitive process, and the existence of the relevance-oriented cognitive model enables the speaker and the hearer to cooperate with each other and understand the implied meaning of each other's words [8]. But relevance depends on context; contextual effects and the listener's efforts to understand the utterance determine the degree of relevance. In order to achieve the optimal relevance, the speaker and the hearer are supposed to work together. The speaker should clearly state his intention, and the hearer should deduce the speaker's intention according to the information provided. When the hearer makes the least effort to achieve the best contextual effect and the right balance of validity and mental effort, the optimal relevance will be achieved.

Relevance theory advocates a dynamic cognitive context that embraces the context of linguistic signs, the specific space-time context in which the speech act occurs, the relevant communicative context, the encyclopedic knowledge stored in people's memory and the belief system under certain cultural background. Therefore, in actual discourse communication, the concrete factors of communication and the information in the hearer's cognitive context will play a certain role in discourse understanding. In order to understand the speaker's intention, the hearer uses the acquired information to establish the optimal relevance between the speaker's utterance and the actual reference through the context. The more closely connected a discourse is to its context, the easier it is to reason and the easier it is to understand. Metaphor, as a special discourse, is a speaker's choice of language in a specific 
context. Thus, the comprehension of metaphor becomes a process of cognitive reasoning of language, understanding the pragmatic intention of the writer through association and inference.

\subsection{Relevance Theory of Translation}

The first scholar to apply relevance theory to translation studies is Gutt of Germany. On the basis of relevance theory, he puts forward relevance translation theory, which holds that the interpretation and implementation of translation process should be carried out from the perspective of communicative competence and communicative effect [9]. In his view, translation is a dynamic cognitive process of ostension and inference. Ostension means that the author of the original text indicates his communicative intention to the translator, while inference means that the translator seeks the best relevance according to the information and specific context provided by the author of the original text by means of ostensive inference, so as to deduce the communicative intention of the author of the original text and understand the text. The author of the original text, the translator and the reader of the translated text interact in this process. Because the readers of the source text and the target text often differ in terms of cognitive context, and the author of the source text usually unconsciously omits the cultural information mutually understood by himself and the source text readers when constructing the specific information, the translator naturally assumes the role of intermediary or bridge. His basic task is to correctly recognize and deal with the optimal relevance that matches the original author's communicative intention, and convey the cognition and understanding of the source language to the target readers in the best way. At the same time, it is also necessary to ensure the dynamic adaptation of the original author in a cognitive and harmonious way, so as to enable the target readers to effectively grasp the original author's intention, satisfy their aesthetic expectation and reception ability, and achieve the successful realization of cross-cultural communication [10]. In other words, it is the responsibility of the translator to strive to conform the intention of the author of the original text to the expectations of the target readers. As Gutt said, translation should do two things: first, the translation should be fully relevant to the target readers, that is, to provide adequate contextual effects; second, the translation should not be presented in such a way that the reader makes any unnecessary effort to achieve the desired understanding [9]. In the process of translation, the translator acts as a discourse transmitter and needs to make full use of the principle of relevance and choose appropriate strategies to deal with the cultural differences between the source language and the target language, in order to achieve the equivalence and expectation between the original author's intention and the target readers' cognition [11]. This process involves both semantic and contextual aspects, in which the translator must not only transcode the literal meaning of the source language, but also choose the right way of expression in the context of the original text and the cognitive context formed by various factors that affect the readers.
The interpretation of context and relevance from the perspective of relevance theory will undoubtedly provide useful guidance for Chinese-English translation, especially for the translation of cultural information from the source language. As the carrier of rich cultural information, colloquial metaphors in Chinese political discourse require the translator to seek the optimal relevance between Chinese cognitive context and English cognitive context.

\subsection{The Pursuit of Optimal Relevance in Colloquial Metaphor Translation}

After thousands of years of development, Chinese culture is broad and profound. Colloquial expressions, created by the masses, are characterized by their colloquial and popular features. They are concise and figurative, in which metaphors are often used to express feelings and wishes. In social life, colloquial expressions promote interpersonal communication, making communication more characteristic and more interesting. As the carrier of human material culture and spiritual culture, colloquial metaphors contain rich national and cultural information. The cultural and national features of metaphor often stand in the way of translation, and it is not easy to find the corresponding translation of these metaphors. To some extent, the degree of the target language readers' resonance to the cultural background and semantic relevance of the source metaphor has become the criterion to judge the success of metaphor translation [3].

In the process of translation, it is easier to understand the essence of metaphor translation by examining, understanding and translating colloquial metaphor based on relevance theory. In translating colloquial metaphors of cultural images with strong national characteristics, the translator has to deal with the transmission characteristics of the vehicle in the source text and establish the contextual hypothesis from the perspective of the intention of intercultural communication in the source text, find out the best intention of the author, and then transfer the cultural image of the source text to the target text fully and accurately through appropriate strategies. Translators can flexibly choose translation methods such as literal translation, free translation and zero translation [12] to reduce the reading barriers caused by cultural differences between China and the West, and help the target readers find the optimal relevance between the source text and the target text as well as the context. Thus the target language readers can achieve the maximum contextual effect with the least effort, correctly convey the implied meaning behind the metaphor in political discourse, and achieve the purposes of political diplomacy and cultural communication.

\section{Cognitive-pragmatic Strategies for Colloquial Metaphor Translation}

《习近平谈治国理政第二卷》[13] (The English version is Xi Jinping: The Governance of China (Volume II) [14], hereafter Governance II) contains important works published by President Xi Jinping from August 2014 to September 2017. 
The book contains his new thoughts of governing the country and government. It is an ideal choice for readers at home and abroad to understand the political ideas of China in the new era. The English version of the book, translated by authoritative experts, can be regarded as a model of similar political texts. The translation ideas and strategies embodied can provide an effective and reliable guide for the translation of political metaphors. In addition to the examples of colloquial metaphors mentioned in previous parts, Xi used many other colloquial metaphors in his speeches in Governance $I I$ to express his views and attitudes in an euphemistic and explicit manner. For instance, to express that though a thing or an organization is small, it has everything needed, "麻雀虽小、五脏俱全" is applied; to urge people to be brave in the face of difficulties at work, "明知山有虎、偏 向虎山行" is used; to state that one cannot be an officer and be rich at the same time, "鱼和熊掌不可兼得" is adopted; to warn that officials should not form cliques for personal gain, " 醉翁之意不在酒" is chosen; to indicate that shared development is realized step by step, "一口吃不成胖子" is employed; and to warn that China should not blindly copy other countries' political system, or it will lead to serious consequences, "画虎不成反类犬" is utilized.

Statistical analysis shows that there are as many as 36 colloquial metaphors in Governance II, of which the most frequently used is "牵牛鼻子" (attend to specific and critical problems), which appears six times in the book. This paper makes a statistical analysis of the translation methods of these colloquial metaphors, and the results are as follows:

Table 1. Translation methods of colloquial metaphors in Governance II.

\begin{tabular}{lllll}
\hline $\begin{array}{l}\text { Translation } \\
\text { methods }\end{array}$ & $\begin{array}{l}\text { Literal } \\
\text { translation }\end{array}$ & $\begin{array}{l}\text { Free } \\
\text { translation }\end{array}$ & $\begin{array}{l}\text { Zero } \\
\text { translation }\end{array}$ & Total \\
\hline $\begin{array}{l}\text { Number } \\
\text { Percentage }\end{array}$ & 11 & 19 & 6 & 36 \\
\hline
\end{tabular}

As shown in Table 1, the translator mainly adopts the methods of literal translation, free translation and zero translation in translating colloquial metaphors into English, among which free translation is most frequently used, followed by literal translation. From the perspective of cognitive-pragmatic relevance translation, it is found that the colloquial metaphor translation strategies in Governance II can be categorized into the following three types.

\subsection{Maintaining the Consistency of the Cognitive Contextual Effects Through Literal Translation}

Whether the target language readers can get the communicative intention from all the linguistic features of the target language depends on whether the cognitive context of the target language readers is consistent or similar to that of the original author. Generally speaking, if the cognitive context of the target text reader is identical or similar to that of the original author, or if the implied meaning of the words containing cultural information in the original text is more obvious or easy to infer, and it is easy for the reader to infer and grasp the implied meaning of these words from the literal meaning, then the translator can adopt literal translation. Literal translation refers to the interpretation of the target text which is exactly similar to the original text and maintains the similarity of the linguistic features between the target text and the original text. Literal translation can be used to explain the semantic and pragmatic meaning of discourse [12]. For example, "打铁还需自身硬" is translated as "a good blacksmith to forge good tools";"搬起石头砸自己的脚" is also literally translated into "lifting rocks only to drop them on their own feet", and similarly, "金无足赤, 人无完人" is interpreted as "there is no pure gold, nor are there perfect people".

These metaphors contain universal concepts and images that all human beings can perceive and express. According to relevance translation theory, in such cases, literal translation can enable the target readers to obtain adequate contextual effects without unnecessary reasoning efforts, achieve optimal relevance and obtain the same implied meaning as Chinese readers. In such a way, the target language readers can understand the expressions, thinking patterns and cultural information behind the source language, maintaining the consistency of the cognitive contextual effects between the source language author and the target language reader. Certain examples are quoted here to illustrate the point in detail.

Example 1

Source text: 改革开放胆子要大一些, 敢于试验, 不能像 小脚女人一样。看准了的, 就大胆试, 大胆地闯。

Translation: We should be bolder than before in conducting reform and opening up to the outside and have the courage to experiment. We must not act like women with bound feet. Once we are sure that something should be done, we should dare to experiment and break a new path.

"小脚女人" is a metaphor for a conservative person. This expression originated from a bad habit of Chinese feudal society, commonly known as foot binding. That is, a woman's feet were wrapped in cloth to make them become small and pointed. This custom was closely related to the aesthetic standards of the society at that time. In modern Chinese political discourse, this expression is often used to imply a timid person who is restrained in doing things, as Mao Zedong put it in his book $O n$ the Cooperative Transformation of Agriculture, "我们的某些同志却象一个小脚女人, 东摇西摆地在那里走 路,老是埋怨旁人说：走快了, 走快了" ("Some of our comrades, like a woman with bound feet, waddle about, always complaining to others and saying, 'go faster, go faster"'). In his speech, Xi quoted Deng Xiaoping to highlight his contribution to China's reform and opening up. The cognitive context of the source language reader can help them understand the implied meaning of the metaphor quickly. While since there is no corresponding metaphor of "小脚女人 "in target language readers' cognitive context, it will cause some trouble to them, which will not only lead to their expense of unnecessary effort, but also the failure to achieve the best communication effect. The translator, therefore, translates it directly into "women with bound feet" without adding any additional comments. In fact, although there is no corresponding image in the cultural context where the readers 
live, because human beings share the same physiological structure and the same psychological basis, including synaesthesia, considering the similarity of the objective world and the commonness of the potential cognitive context, the readers of the target text, in combination with their daily cognitive experience, can produce the relevant metaphorical meaning in their mind and successfully understand the information conveyed by the target text. Moreover, the study finds that "women with bound feet" has been used to cover the cultural phenomenon on CNN. It can be said that this phenomenon of Chinese traditional culture has been known to the world. The literal translation retains the information and metaphorical features of the original text to the maximum extent and realizes the optimal relevance. Therefore, the reader of the translation can, with the least effort, interpret the deep meaning, that is, not to be constrained in the way that a woman bound by her feet can be constrained, according to the context and the cognitive ability of the translator.

Example 2

Source text: 干这种事, 最后都会搬起石头砸自己的脚, 机关算尽反而误了卿卿性命。

Translation: Those who do so will find themselves lifting rocks only to drop them on their own feet. They may be relentless in their scheming, but they only end up bringing about their destruction.

"搬起石头砸自己的脚" is a metaphor for trying to hurt others, but it ends up hurting oneself. In Governance II, the expression is translated word-for-word as "lifting rocks only to drop them on their own feet", which shows the complete vocabulary, syntax and semantic structure of the original text to the target language readers. The readers do not have to expend the inference effort to be able to understand the implied meaning. Considering the current development trend of China, a pure literal translation of metaphors in political discourse is helpful for the outside world to understand China. Perhaps foreign readers will understand and accept Chinese culture as we are accustomed to English expressions like "Achilles".

\subsection{Enhancing the Accessibility of the Cultural Context via Free Translation}

Because the national and cultural characteristics of colloquial expressions, to a certain extent, influence the difference of cognitive domain between the original author and the target readers, the explicit information of the source text may fail to activate the relevant contextual assumptions in the target readers' minds and lose relevance. In order to faithfully and effectively show the essence of the original ideas, enhancing the accessibility of the cultural context between the source language author and the target language reader through free translation is a good strategy. Free translation refers to the retention of the basic meaning or cognitive effect of the source text without retaining the linguistic features of the source text. In other words, if the target readers have little knowledge of the relevant culture of the source language, or if the cognitive context of the target readers is not quite equivalent to that of the source language authors, or if the implied meaning of the culture-loaded words in the source language is more obscure, in order to improve the accessibility of the cultural context between the source language author and the target language reader and achieve effective communication, the translator can adopt the method of free translation. In this way, the cultural images of the source text and the target text are closely related and tend to coincide within a certain range of error [15]. For example, "山高皇帝远" means "higher-level supervision is distant"; "一叶障目, 不见泰山" is translated into "adopt a one-sided perspective", and "当一天和尚撞一天钟" is understood as "content with the status quo and perfunctory in their work".

Additionally, there are metaphors in target language which have the same pragmatic function as the source language metaphors, such as "papering over the cracks" which can be directly used to translate "和稀泥" and "have the cake and eat it" to translate "鱼和熊掌不可兼得". This phenomenon further indicates that in the process of translating colloquial political metaphors, translators pay more attention to the effect of information transmission and the realization of the pragmatic function of the target text, rather than maintaining formal linguistic consistency or maintaining the cultural identity of the source language. For instance, the expression " 牛鼻子" is used to describe the key that affects the whole situation. It appears six times in the original text. The translator does not translate it literally as "the nose of an ox", but mainly adopts free translation and translate it respectively into "critical problems", "the key" and "prominent feature".

Obviously, when the cognitive context of the source language author and the target language reader is not quite equal, the translator can give up the form or even the cultural image of the source language and focus on its pragmatic meaning. With the application of free translation, the translator can synthesize the context, reproduce the communicative intention and improve the accessibility of the cultural context, so as to achieve the optimal relevance. Example 3 and 4 better illustrate this point.

Example 3

Source text: 如果心中只有自己的一亩三分地, 拘泥于部 门权限和利益, 甚至在些具体问题上讨价还价, 必然是磕 磕绊绊, 难有作为。

Translation: If we limit ourselves to our own little world, dwelling on the powers and interests of departments and haggling over minor issues, the result will surely be limited progress achieving little or nothing of real import.

"一亩三分地"-fame from the Ming and Qing dynasties, referring to the area of land that the emperor was supposed to till. It was later extended to mean "my own little place", "my own sphere of influence". "Mu" and "Fen" are the traditional Chinese units of area measurement, and it is also symbolic to determine the size of the emperor's farmland by "one" and "three". However, such historical and cultural background of the original text does not exist in the target language. If literal translation with notes is used, it will not only cost a lot of ink, but also will fail to show the communicative intention of the original author. The target readers have to make great efforts to understand the basic meaning and the figurative meaning of 
the source text, so the optimal relevance can not be achieved. Therefore, the translator paraphrases it as "little world", and the target readers can understand its meaning more efficiently, realize the connection between their own cognition and the cognition of the source language, and obtain the optimal relevance.

Example 4

Source text: 有的人只要是他工作过的地方, 全要搞成他 自己的领地, 到处插手人事安排, 关照自己小圈子里的人, 结果他们就成了一根绳上的蚂虾。

Translation: Some officials use their power to create "formal" factions and turn the places they administrate into their fiefdoms, where they meddle and intervene in personnel matters in favor of those in their own faction. Consequently, when one goes down, they will take all the others with them.

"一根绳上的蚂虾" is a typical Chinese colloquial metaphor, referring to two things that are closely related, inseparable. This idiom is often used in political discourse to describe people who break the law and discipline, take bribes and are severely punished. Speaking at the Fifth Plenary Session of the Party's eighteenth Central Commission for Discipline Inspection, $\mathrm{Xi}$ stressed with this metaphor that the party does not allow gangs, otherwise they will violate political discipline and will be punished accordingly. If we translate it literally as "grasshoppers tied to the same rope", the cognitive environment will not help readers who are not familiar with Chinese culture to understand, which might even increase the efforts involved in understanding. For this reason, the translator gives up the linguistic form and cultural image of the source text and adopts free translation to express the pragmatic meaning of the source text and the author's communicative intention on the basis of context, so as to achieve the optimal relevance.

\subsection{Strengthening the Relevance by Means of Zero Translation}

Some of the colloquial metaphors in Governance II have a very strong Chinese historical and cultural background, which makes the cognitive context of the original language author and the target language reader quite different, and the translator tends to adopt zero translation to strengthening the relevance. Under this circumstance, it is probably a pity for the translator to fail to display the rich cultural features of the source language, but the target language readers can understand the pragmatic intention of the source language author with the minimum cognitive effort, realizing the enhancement of the relevance between the source language author and the target language readers.

Example 5

Source text: 在任何工作中, 我们既要讲两点论, 又要讲 重点论, 没有主次, 不加区别, 眉毛胡子一把抓, 是做不好 的。

Translation: In every aspect of our work, we should address both major and minor problems and both major and minor aspects of a problem, while focusing on major issues and major aspects of a problem. Different problems cannot be solved by undifferentiated measures.
"眉毛胡子一把抓" originated from a Chinese novel in 1950s. This idiom is closely related to the current situation of Chinese society at that time and the personal experience of the writer Li Yingru. It is often used in political discourse as a metaphor for doing things without priority. For example, Premier Li Keqiang once used it to indicate that to deepen the reform, the major points should be highlighted; Xi quoted this proverb in his speech at the twenty collective study session of the 18th Politburo to emphasize that work should be comprehensive and focused, and that different objects should be treated differently. There is no such metaphor in the cognitive environment of the target readers, so it is impossible for the English readers to understand the metaphor with the help of the relevant historical and cultural background. In this case, the translator did not translate it literally as "grasp the eyebrows and the beard at the same time", but chose to omit it. The choice of zero translation reduces the reader's effort to understand the metaphor and achieves a more effective understanding of the source text.

Example 6

Source text: 对各种项目、投资、金融活动，要深入研判、 评估风险，不能见钱眼开，有奶就是娘。

Translation: Careful analysis must be made before making investment or engaging in projects and financial activities. Sound judgement must be exercised, and the risks must be evaluated. We must not be tempted by money.

"有奶就是娘" is from the Chinese master Lu Xun. It is often used as a metaphor for those who forsake righteousness for profit. In the process of translation, the translator may not be able to find an interpretive translation which is exactly similar to the source text. So the translator omits the translation of the colloquial metaphor by combining the cognitive context of the target reader with the contextual information of the source text. In this way, the target readers can achieve adequate contextual effects without unnecessary effort, and the communicative intention of the original author can be accurately conveyed.

\section{Conclusion}

Colloquial metaphor is one of the prominent characteristics of Chinese political discourse, and relevance theory and relevance translation theory play an important role in the translation of languages with distinctive cultural characteristics. In the process of translation, the translator should be guided by the theory and principle of relevance translation, and relate the original text itself to its historical and cultural background, taking into full account the differences between the cognitive context of the author of the original text and that of the target readers. And translation strategies like maintaining, promoting and strengthening the relevance between the author and the target language readers respectively through literal translation, free translation and zero translation can be adopted, in order to convey the author's pragmatic communicative intention accurately, and enable the target readers to obtain enough explicit information with minimal effort, deduce the communicative intention of the 
target text and achieve successful communication.

\section{Acknowledgements}

The author wishes to acknowledge the support from the project "A Study of Pragmatic Translation Strategies for Xi Jinping's Political Discourse" (Project Code: 2019 GZGJ205), the project "A study on the English Translation Strategies and Communication Effects of Xi Jinping: The Governance of China in the New Era" (Project Code: 2017WQNCX206), and the team project of South China Business College "The Characteristic and Cross-cultural Translation of Diplomatic Discourses of China" (Project Code: 2019-42).

\section{References}

[1] Lakoff G., Johnson M. (2003). Metaphors We Live By. University of Chicago Press.

[2] Wang X. J. (2014). On Metaphor-in Memory of Mr. Wang Dechun. English studies. (4), 1-4.

[3] Lei X. F., Tian J. G. (2014). A Study of Metaphor Translation in the Framework of Pragmatic Adaptation Theory. Foreign Language Teaching. (2), 99-103.

[4] Sperber D., Wilson D. (1995). Relevance: Communication \& Cognition. Oxford: Blackwell.
[5] Yuan Z. X., Tang S. H. (2019). On Metaphor in Political Discourse and Its English Translation Strategies. Journal of the Inner Mongolia Agricultural University. (1), 85-89.

[6] Ji Y. (2018). Conceptual Metaphor Analysis of General Secretary Xi Jinping's Political Discourse. Journal of the North University of China. (5), 120-125 + 130.

[7] Zhao Y. C. (1999). The Explanatory Power of Relevance Theory to Translation. Modern Foreign Languages. (3), 276-295.

[8] He Z. R., Ran Y. P. (2009). An introduction to Pragmatics. Beijing: Peking University Press.

[9] Gutt E. A. (2004). Translation and Relevance: Cognition and Context. Shanghai Foreign Language Education Press.

[10] Liu B. R. (2014). Cognitive Pragmatics and Translation Studies. Journal of Northeast Normal University. (6), 151-155.

[11] Li X. Y. (2012). Translation of Common Sayings from the Perspective of Relevance Theory. French Learning. (6), 36-41.

[12] Mo A. P. (2011). The Pragmatic Approach to Translation Studies. Foreign Languages in China. (3), 90-96.

[13] Xi J. P. (2017). Xi Jinping Tan Zhi Guo Li Zheng (Di Er Juan). Beijing: Foreign Languages Press.

[14] Xi J. P. (2017). Xi Jinping: The Governance of China (Volume II). Beijing: Foreign Languages Press.

[15] Liu F. G. (2008). A Study of The Metaphor Translation Principles. National Defense Industry Press. 